\title{
BMJ Open Prevalence and predictors of poor sexual well-being over 5 years following treatment for colorectal cancer: results from the ColoREctal Wellbeing (CREW) prospective longitudinal study
}

\author{
Jane Frankland, ${ }^{1}$ Sally Wheelwright, ${ }^{1}$ Natalia V Permyakova, ${ }^{1}$ David Wright, ${ }^{1}$ \\ Nicole Collaço, ${ }^{1}$ Lynn Calman, ${ }^{1}$ Jane Winter, ${ }^{2}$ Deborah Fenlon, ${ }^{3}$ \\ Alison Richardson, ${ }^{2,4}$ Peter W Smith, ${ }^{5}$ Claire Foster (D) ${ }^{1}$
}

To cite: Frankland J, Wheelwright S, Permyakova NV, et al. Prevalence and predictors of poor sexual wellbeing over 5 years following treatment for colorectal cancer: results from the ColoREctal Wellbeing (CREW) prospective longitudinal study. BMJ Open 2020;10:e038953. doi:10.1136/ bmjopen-2020-038953

- Prepublication history and additional material for this paper are available online. To view these files, please visit the journal online (http://dx.doi org/10.1136/bmjopen-2020038953).

Received 30 March 2020 Revised 22 July 2020 Accepted 09 October 2020

Check for updates

(C) Author(s) (or their employer(s)) 2020. Re-use permitted under CC BY-NC. No commercial re-use. See rights and permissions. Published by BMJ.

For numbered affiliations see end of article.

Correspondence to Professor Claire Foster; C.L.Foster@soton.ac.uk

\section{ABSTRACT}

Objectives To describe prevalence and predictors of poor sexual well-being for men and women over 5 years following treatment for colorectal cancer.

Design Prospective longitudinal study, from presurgery to 5 years postsurgery, with eight assessment points. Logistic regression models predicted sexual well-being from presurgery to 24 months and 24 months to 60 months; time-adjusted then fully adjusted models were constructed at each stage.

Setting Twenty-nine hospitals in the UK.

Participants Patients with Dukes' stage A-C, treated with curative intent, aged $\geq 18$ years and able to complete questionnaires were eligible.

Outcome measures The dependent variable was the Quality of Life in Adult Cancer Survivors sexual function score. Independent variables included sociodemographic, clinical and psychosocial characteristics.

Results Seven hundred and ninety participants provided a sexual well-being score for at least one time point. Thirty-seven per cent of men and $14 \%$ of women reported poor sexual well-being at 5 years. Baseline predictors for men at 24 months included having a stoma (OR 1.5, $95 \% \mathrm{Cl} 1.02$ to 2.20 ) and high levels of depression (OR $2.69 / 2.01,95 \% \mathrm{Cl} 1.68$ to $4.32 / 1.12$ to 3.61 ); men with high self-efficacy (OR confident $0.33 / 0.48,95 \% \mathrm{Cl} 0.18$ to $0.61 / 0.24$ to 1.00 ; very confident $0.25 / 0.42,95 \% \mathrm{Cl} 0.13$ to $0.49 / 0.19$ to 0.94 ) and social support (OR $0.52 / 0.56$, $95 \% \mathrm{Cl} 0.33$ to $0.81 / 0.35$ to 0.91 ) were less likely to report poor sexual well-being. Predictors at 60 months included having a stoma (OR 2.30/2.67, $95 \% \mathrm{Cl} 1.22$ to $4.34 / 1.11$ to 6.40 ) and high levels of depression (OR 5.61/2.58, 95\% Cl 2.58 to $12.21 / 0.81$ to 8.25 ); men with high self-efficacy (very confident $0.14,95 \% \mathrm{Cl} 0.047$ to 0.44 ), full social support (OR $0.26 ; 95 \% \mathrm{Cl} 0.13$ to 0.53 ) and higher quality of life (OR $0.97,95 \% \mathrm{Cl} 0.95$ to 0.98 ) were less likely to report poor sexual well-being. It was not possible to construct models for women due to low numbers reporting poor sexual well-being

Conclusions Several psychosocial variables were identified as predictors of poor sexual well-being among men. Interventions targeting low self-efficacy may be

\section{Strengths and limitations of this study}

- This is the largest prospective longitudinal study to report the sexual well-being of people treated for colorectal cancer.

- The cohort was followed from a presurgery assessment up to 5 years postsurgery, with a total of eight assessment points.

- The cohort is a representative sample which achieved very high response rates $(88 \%-71 \%$ over 5 years)

- Women were more likely to return a non-response to sexual well-being questions than men (12\% vs $4 \%$ overall).

- Small numbers of women with poor sexual wellbeing meant that logistic regression models could not be constructed.

helpful. More research is needed to understand women's sexual well-being.

\section{INTRODUCTION}

Cancer and its treatment can adversely affect a person's sex life. Across cancers, different treatments can cause physical side effects which may lead to sexual problems such as loss of interest in sex (libido), and functional problems such as erectile and ejaculatory problems for men, and dyspareunia (painful intercourse) and vaginal dryness or atrophy for women. ${ }^{1-8}$ In addition, changes to body image and other symptoms, such as pain, anxiety and fatigue may contribute. Sexual problems can be short term but can also be a late effect of treatment and can continue long term. Many people living with and beyond cancer do not feel prepared for these consequences nor receive adequate support. ${ }^{9}$ 
Research into the effects of cancer treatment on sexual health has often taken a medicalised approach, with emphasis solely on function. ${ }^{10}{ }^{11}$ Such a focus fails to account for the patient's perspective, ${ }^{12}$ neglecting the subjective meaning of functional changes. ${ }^{13} 14$ In contrast, sexual well-being refers to an individual's assessment or evaluation of their sexual life, ${ }^{1115}$ and thus is a concept which is broader than function. Sexual well-being is part of overall sexual health ${ }^{16}$ and an important contributor to quality of life. ${ }^{17}$ While poorly operationalised in the literature, ${ }^{15}$ and used interchangeably with the terms 'sexual quality of life/quality of sexual life', it is acknowledged as a multifaceted construct, and has been variously operationalised to include a range of dimensions within the individual-cognitive-affect (eg, function, satisfaction), interpersonal (eg, relationship well-being, intimacy) and sociocultural (eg, norms, stereotypes, socialisation) domains, with function and satisfaction being the most common measures used. ${ }^{15}$ Reported levels of sexual wellbeing do not always correspond to reports of function, with reports of well-being despite reduced function. ${ }^{18}$ Greater insight will be gained by the study of well-being as well as function. To date, studies of sexual well-being among people living with and beyond cancer have commonly focused on reproductive cancers, and an understanding of other cancers is needed. ${ }^{14}$ In addition, there is commonly a focus on clinical rather than psychosocial associates and predictors of sexual well-being. However, Foster and Fenlon's framework of recovery of health and well-being following cancer suggests the importance of personal factors (such as personality, affective dispositions and general self-efficacy) and environmental factors (such as social support) in influencing coping and recovery, indicating the importance of including such factors as predictors of sexual well-being over time. ${ }^{19}$

Colorectal cancer is the third most common cancer worldwide, with 1.8 million new cases in 2018 representing $10.2 \%$ of all new cancers. ${ }^{20}$ Sexual dysfunction following treatment for colorectal cancer is common and well documented, with levels typically higher than the normative population. ${ }^{21}{ }^{22}$ Research has identified demographic and treatment factors associated with sexual dysfunction among people who have been treated for colorectal cancer, for instance, age (older people having more sexual problems ${ }^{4822-25}$ ) and type of treatment (eg, people receiving radiotherapy can experience significant impairment in function ${ }^{4}$ ). In addition, having a stoma may affect intimacy, body image and sexual frequency. ${ }^{182326-28}$ Psychosocial factors associated with sexual dysfunction have received less attention, ${ }^{24}{ }^{29}$ but include depressive symptoms, emotional well-being and partner relationship quality. ${ }^{422}$

As with other cancer types, the sexual well-being of people living with and beyond colorectal cancer is less well documented than sexual function. No studies which purported to assess predictors of sexual well-being were found, though a small number of studies used indicators of sexual well-being within broader quality of life studies, and two recent studies focused on quality of sexual life. A review of papers addressing quality of sexual life up to 2010 indicates that type of cancer and type of treatment are related to satisfaction/sexual enjoyment, with equivocal findings for stoma. ${ }^{29}$ Among men, satisfaction decreased after treatment and low satisfaction endured long term. The review found no studies considering satisfaction for women. ${ }^{29}$ The more recent studies indicate different patterns of sexual quality of life for men and women, with quality of sexual life reducing with time. ${ }^{25}$ Reported predictors of low quality of sexual life were depressive symptoms, having rectal cancer, ${ }^{25}$ and associations have been reported between sexual distress and relationship quality, depression and health related quality of life, and between perceived impact of treatment and depression and quality of life. ${ }^{30}$ The majority of these studies were limited by being cross-sectional and having small sample sizes. ${ }^{29}$ Few studies have explored associations between self-efficacy and sexual well-being, and none with colorectal cancer patients specifically. Within other cancer types, associations have been shown between self-efficacy and sexual well-being outcomes for women with breast cancer (sexual self-efficacy) ${ }^{31}$ but not men with prostate cancer (self-efficacy for symptom control).$^{32}$ Correlations have been shown between sexual distress and psychosocial variables including sexual selfefficacy and self-efficacy to communicate about sex and intimacy (SECSI) for women with various cancer types. ${ }^{33}$

Within this context, there is a need for larger, longerterm longitudinal studies to understand changes in sexual well-being and predictors over time. ${ }^{35}$ Taking account of the gendered nature of sexual well-being and its predictors, ${ }^{34}{ }^{35}$ it is important to do this for men and women separately. This need is addressed here through analysis of data from the UK ColoREctal Wellbeing study (CREW), a large-scale prospective cohort study of a representative sample of people diagnosed with colorectal cancer and treated with curative intent, investigating factors associated with recovery of health and well-being. ${ }^{36}$

The aim of the paper is to investigate men and women's sexual well-being from a pre-surgery baseline to 24 months postsurgery, and from 24 to 60 months postsurgery. Here, sexual well-being is defined as an individual's subjective assessment of their sexual function and is operationalised using a subdomain of sexual satisfaction and bother within a quality of life measure. The 24-month post-treatment time point is significant because, although surveillance commonly continues beyond this point, ${ }^{37} 38$ treatment has usually ended and there may be fewer faceto-face opportunities to discuss problems with a healthcare professional. ${ }^{39}$ In the UK, for example, policy embeds a stratified approach to follow up care for people with colorectal cancer, meaning that the majority will experience a supported self-management approach to care in the latter years of follow-up. ${ }^{40}$ The following questions are addressed in the paper: (1) What is the prevalence of poor sexual well-being among men and women with colorectal cancer from pre-surgery and up to 60 months 
postsurgery; (2) which presurgery sociodemographic and psychosocial variables are associated with poor sexual well-being for men and women (separately) over 24 months and (3) which treatment, sociodemographic and psychosocial variables at 24 months are associated with poor sexual well-being for men and women (separately) onwards to 60 months?

\section{METHOD}

\section{Design}

CREW is a multicentre prospective, longitudinal cohort study of a representative sample of people newly diagnosed with colorectal cancer undergoing curative intent surgery. Full details of the aims and methods of the study are provided elsewhere. ${ }^{36}$

\section{Patient and public involvement}

People affected by cancer were involved from the early stages of the project, through a launch event to talk about study design. Research questions were informed by a previous study asking people living with and beyond cancer about their concerns. ${ }^{41}$ People living with and beyond cancer were also involved in the Study Advisory Committee, through which they had input into study processes and plans for dissemination. They helped support recruitment through involvement in site meetings with recruiting hospitals and in a project film to promote the study.

\section{Participants}

Eligible participants had a diagnosis of non-metastatic colorectal cancer (Dukes' A-C); were being treated with curative intent surgery; $\geq 18$ years old and had the ability to read and understand English. People who had had another cancer diagnosis prior to their colorectal cancer were excluded.

\section{Procedure}

Participants were recruited from 29 UK hospitals between November 2010 and March 2012. Baseline questionnaires were completed before primary surgery (baseline), with subsequent follow-up questionnaires mailed at 3, 9, 15 and 24 months and then annually up to 60 months. The questionnaires comprised both validated measures and additional questions to assess domains identified in Foster and Fenlon's ${ }^{19}$ framework of recovery of health and well-being in cancer survivorship..$^{19}$ Clinical and treatment data (stage, grade of disease, type of treatment) were gathered from participants' National Health Service (NHS) medical records at 6 months and verified at 24 months postsurgery.

All participants provided written informed consent.

\section{Measures}

Full details of the measures used in the study have been reported elsewhere. ${ }^{36}$ A summary of the measures used is included in online supplemental table 1 . Only sociodemographic, clinical and psychosocial variables hypothesised to be relevant to sexual well-being were included in the analyses, and these are described here.

\section{Sexual well-being}

The main outcome was sexual well-being, operationalised using the 'sexual function' domain of a quality of life measure-the Quality of Life in Adult Cancer Survivors (QLACS) scale. $^{42}$ The QLACS contains 47 items and 12 domains. Questions pertain to the previous 4 weeks and are scored as 1-7 (never, seldom, sometimes, as often as not, frequently, very often, always). The QLACS sexual function domain includes two questions: 'You were bothered by being unable to function sexually' and 'You were dissatisfied with your sex life'. The two scores are summed to give the domain score, ranging from 2 to 14, with higher scores indicating poorer sexual well-being. The score was highly skewed towards better sexual well-being in both men and women with median scores of 4 and 2, respectively (see online supplemental figure 1). Because of this, and for purposes of clinical interpretation, we chose to dichotomise the variable rather than examine scores continuously. In the absence of published cutoffs for the measure, we defined poor sexual wellbeing as scores greater than seven, to incorporate bother and dissatisfaction which was 'as often as not' or more frequent.

The sexual interest scale of the QLACS, which comprises the questions: 'You lacked interest in sex,' and 'You avoided sexual activity' was included in the description of baseline characteristics. With the same reasoning as above, a score of greater than seven was used to indicate a lack of interest in sex.

\section{Sociodemographic, clinical and treatment data}

Sociodemographic variables which are indicated in the literature as associated with sexual function/ well-being were included. Self-reported sociodemographic data collected included employment status and domestic status. Index of Multiple Deprivation quintiles were derived from postcodes. ${ }^{43}$ Tumour site, type of surgery, age and additional treatment (radiotherapy and/or chemotherapy) were collected from NHS medical records.

\section{Self-efficacy}

No previous studies were found which assessed an association between self-efficacy and sexual wellbeing, however, previous analysis of the CREW data set has indicated that self-efficacy is a predictor of quality of life, health status and well-being . It was, therefore, hypothesised that there would be a relationship between low self-efficacy and poor sexual well-being. The Self-efficacy for Managing Chronic Disease (SEMCD) 6-item instrument ${ }^{44}$ was used to assess self-efficacy from baseline to 9 months. From 15 months, the Cancer Survivor Self-efficacy Scale ${ }^{41}$ was used. This scale adds five items to the SEMCD and 
asks about 'your cancer' rather than 'your disease'. For both instruments, all items are scored from 1 (not at all confident) to 10 (totally confident) and a mean score is calculated. The following cut-offs, derived from previous CREW analysis of trajectories of selfefficacy, ${ }^{45}$ were applied to both scales: $1-4$ 'low confidence', 5-6 'moderate confidence', 7-8 'confident' and 9-10 'very confident'.

\section{Depression and anxiety}

Following other studies, ${ }^{22}{ }^{25}$ we hypothesised that high rates of depression and anxiety would be associated with poor sexual well-being. The 20 item Centre for Epidemiological Studies Depression scale ${ }^{46}$ was used to assess depression. Respondents are asked to indicate how often they experience symptoms, indicating the frequency on a 4-point Likert scale. Higher scores indicate more symptoms of depression and scores of $\geq 20$ suggest clinical levels of depression. ${ }^{47}$ The State Trait Anxiety Inventory ${ }^{48}$ was used to measure current anxiety symptoms. Respondents are invited to use a 4-point Likert scale to indicate how often they have experienced 20 items. Greater anxiety is associated with higher scores and scores $\geq 40$ suggest clinically significant levels of anxiety. ${ }^{49}$

\section{Social support}

Low social support is associated with increased risk of sexual dysfunction ${ }^{24}$; we, therefore, hypothesised that low social support would be associated with poor sexual wellbeing. Social support was measured using the Medical Outcomes Study Social Support Survey (MOS-SSS). ${ }^{50}$ The instrument consists of 19 items concerning the availability of different types of support, with responses recorded on a 5-point Likert scale ('none of the time' to 'all of the time'). As this measure is highly skewed, we divided scores on the MOS-SSS into ceiling (feeling fully supported) and below.

\section{Health-related quality of life}

Literature indicates associations between sexual dysfunction/quality of sexual life and global quality of life, ${ }^{24}$ having a stoma, ${ }^{122} 2425$ fatigue ${ }^{24}$ and body image. ${ }^{25}$ We hypothesised pain, fatigue, having a stoma and poor body image to be associated with poor sexual well-being, and high quality of life with good sexual well-being. Quality of life was assessed from 3 months onwards using the European Organisation for Research and Treatment of Cancer Quality of Life questionnaire Core Questionnaire the (the QLQ-C30) ${ }^{51}$ and colorectal cancer module (the QLQ-CR29). ${ }^{52}$ The scales included in this paper were the global health status/quality of life, pain and fatigue scales of the QLQ-C30 and the impotence, dyspareunia and body image scales of the QLQ-CR29. Self-reported stoma status was taken from the QLQ-CR29. For both the QLQC30 and the QLQ-CR29, respondents were asked to what extent each item applied to them, with response options of not at all (1), a little (2), quite a bit (3) or very much (4) for all items except the global health and quality of life items of the QLQ-C30, which uses a seven-point scale. A linear transformation was used for all scales to produce a score between 0 and 100 . Thresholds of clinical importance have been published for the pain $(>25)$ and fatigue (>39) scales $^{53}$ For the QLQ-CR29, clinical importance was indicated if any individual item within a scale received a score of 3 or 4 .

\section{Statistical methods}

All analyses were undertaken separately for men and women. Summary statistics for participant characteristics at baseline (pre-surgery) and the prevalence of poor sexual well-being over the 60 months of the study were calculated.

Two sets of logistic regression models were produced with sexual well-being as a time-varying outcome. The population-average approach was used to combine data for each individual across the required time points for each regression model. Standard Errors were adjusted to account for repeated observations of the same individuals. The first set of models focused on the associations between participant characteristics at baseline and sexual well-being up to 24 months after surgery. The second set of models examined the associations between participant characteristics at 24 months postsurgery (along with timeconstant covariates related to tumour type, treatment and deprivation index quintiles) and sexual well-being over the next 3 years.

Each set of models consisted of two steps: in step 1 , models adjusted for time only (one per covariate) were constructed; in step 2, a fully adjusted model was constructed using the same covariates. A category for missing data was included for a variable if there was $>5 \%$ missing data in that variable. Analyses were performed using Stata V.14 software. Statistical significance was set at $5 \%$ throughout.

\section{RESULTS}

\section{Participants}

The flow of participants through the study has been reported elsewhere. ${ }^{54} \mathrm{~A}$ total of 872 people provided full consent, with response rates between $88 \%$ at baseline and $71 \%$ at 60 months. Of the consented participants, $790 \mathrm{had}$ a sexual well-being outcome on at least one time point throughout the study and are included in table 1 (baseline characteristics), and figure 1 (prevalence of poor sexual well-being).

Prevalence of poor sexual well-being among men and women from presurgery baseline and over 5 years post-treatment

Presurgery baseline reports of poor sexual well-being were significantly associated with having lower selfefficacy, anxiety and depression among men, whereas women were significantly more likely to report poor sexual well-being at baseline if they had radiotherapy (see online supplemental Table 2). Figure 1 shows that men were significantly more likely to report 
Table 1 Baseline characteristics for men $(\mathrm{N}=479)$ and women $(\mathrm{N}=311)$ who provided a sexual well-being score for at least one of the eight assessment points

\begin{tabular}{|c|c|c|c|c|}
\hline \multirow[b]{2}{*}{ Baseline variables } & \multicolumn{2}{|c|}{ Men } & \multicolumn{2}{|c|}{ Women } \\
\hline & $\mathbf{N}$ & $\%$ & $\mathbf{N}$ & $\%$ \\
\hline Total $(\mathrm{N}=790)$ & 479 & 100 & 311 & 100 \\
\hline \multicolumn{5}{|l|}{ Age groups } \\
\hline$\leq 59$ & 75 & 15.6 & 66 & 21.2 \\
\hline $60-69$ & 201 & 42.0 & 105 & 33.8 \\
\hline $70+$ & 202 & 42.2 & 139 & 44.7 \\
\hline Unknown & 1 & 0.2 & 1 & 0.3 \\
\hline \multicolumn{5}{|l|}{ Employment status } \\
\hline Employed & 129 & 26.9 & 72 & 23.2 \\
\hline Unemployed/retired & 308 & 64.3 & 220 & 70.7 \\
\hline Unknown & 42 & 8.8 & 19 & 6.1 \\
\hline \multicolumn{5}{|l|}{ Domestic status } \\
\hline Married/coresiding & 350 & 73.1 & 177 & 56.9 \\
\hline Single/widowed/divorced & 87 & 18.2 & 118 & 37.9 \\
\hline Unknown & 42 & 8.8 & 16 & 5.1 \\
\hline \multicolumn{5}{|l|}{ Deprivation Index Quintiles } \\
\hline First-least deprived & 94 & 19.6 & 60 & 19.3 \\
\hline Second & 112 & 23.4 & 49 & 15.8 \\
\hline Third & 88 & 18.4 & 63 & 20.3 \\
\hline Fourth & 86 & 18.0 & 62 & 19.9 \\
\hline Fifth-most deprived & 88 & 18.4 & 72 & 23.2 \\
\hline Unknown & 11 & 2.3 & 5 & 1.6 \\
\hline \multicolumn{5}{|l|}{ Tumour } \\
\hline Colon & 294 & 61.4 & 211 & 67.8 \\
\hline Rectum & 182 & 38.0 & 100 & 32.2 \\
\hline Unknown & 3 & 0.6 & 0 & 0.0 \\
\hline \multicolumn{5}{|l|}{ Dukes' stage } \\
\hline A & 79 & 16.5 & 35 & 11.3 \\
\hline B & 250 & 52.2 & 174 & 55.9 \\
\hline C1 & 86 & 18.0 & 68 & 21.9 \\
\hline $\mathrm{C} 2$ & 55 & 11.5 & 30 & 9.6 \\
\hline Unknown* & 9 & 1.9 & 4 & 1.3 \\
\hline \multicolumn{5}{|l|}{ Surgery type } \\
\hline Laparoscopic & 267 & 55.7 & 167 & 53.7 \\
\hline Open surgery & 186 & 38.8 & 125 & 40.2 \\
\hline Unknown & 26 & 5.4 & 19 & 6.1 \\
\hline \multicolumn{5}{|l|}{ Radiotherapy } \\
\hline No & 381 & 79.5 & 258 & 83.0 \\
\hline Yes & 95 & 19.8 & 53 & 17.0 \\
\hline Unknown & 3 & 0.6 & 0 & 0.0 \\
\hline \multicolumn{5}{|l|}{ Chemotherapy } \\
\hline No & 296 & 61.8 & 176 & 56.6 \\
\hline Yes & 178 & 37.2 & 132 & 42.4 \\
\hline Unknown & 5 & 1.0 & 3 & 1.0 \\
\hline
\end{tabular}


Table 1 Continued

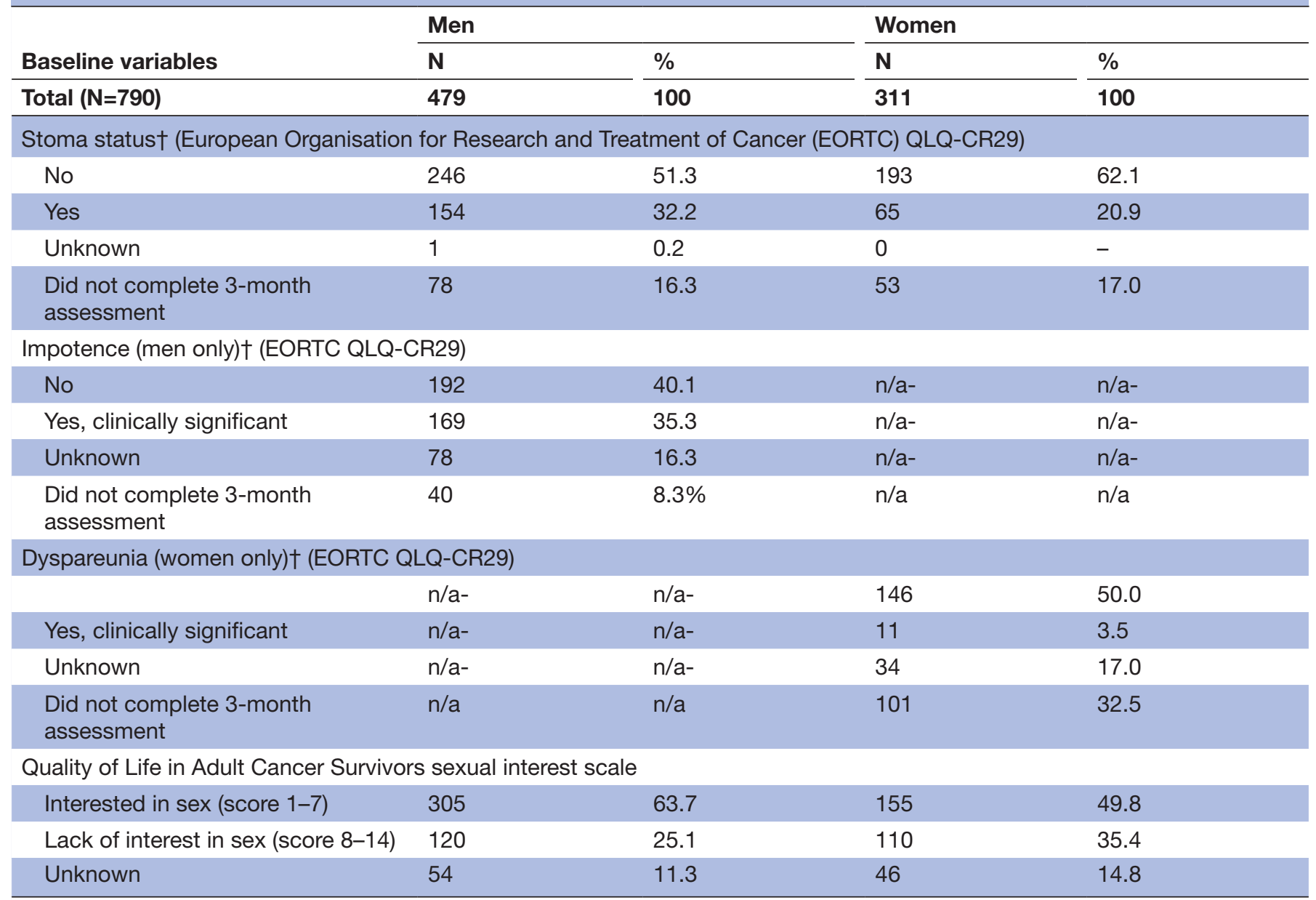

*Dukes' stage could not be determined for 11 full consent patients with small tumours following neoadjuvant therapy. †Reported at 3 months; non-completion of 3-month assessment point is reported. n/a, not applicable.

poor sexual well-being than women both presurgery and throughout the 5 years postsurgery (the $95 \%$ CIs do not overlap between men and women at any time point). The prevalence of poor sexual well-being in women did not change significantly across time points after baseline. In contrast, the prevalence of poor sexual well-being among men significantly increased with respect to baseline (at 9 months and after 24

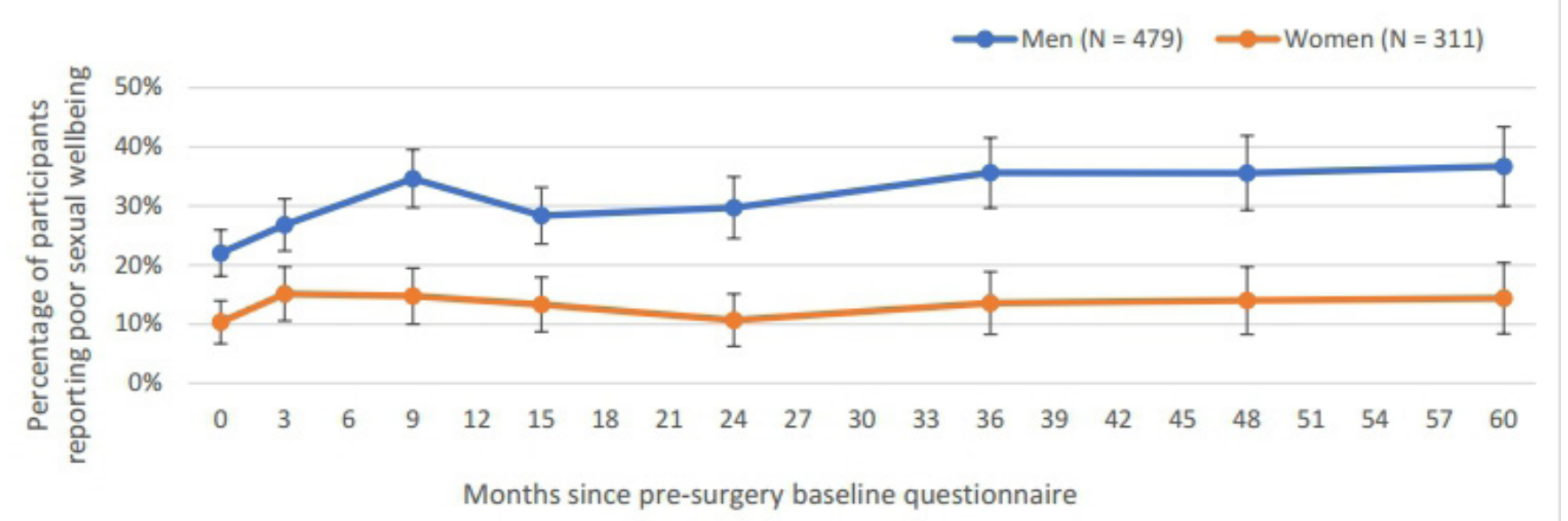

Figure 1 Prevalence of poor sexual well-being among men and women over the 5 years from presurgery baseline, showing $95 \%$ Cls. 
Table 2 Logistic regression modelling (ORs and 95\% Cls) of poor sexual well-being among men between 3 and 24 months by the covariates reported at baseline $(\mathrm{N}=433)$

$\begin{array}{ll}\text { Step } 1^{*} & \text { Step } 2 \dagger \\ \text { OR }(95 \% \mathrm{Cl}) & \text { OR }(95 \% \mathrm{CI})\end{array}$

Age group

$\begin{array}{lll}\leq 59 & \text { REF } & \text { REF } \\ 60-69 & 0.83(0.49 \text { to } 1.41) & 1.11(0.60 \text { to } 2.04) \\ 70+ & 0.77(0.45 \text { to } 1.32) & 0.96 \text { (0.50 to } 1.82)\end{array}$

Deprivation Index Quintiles

First-least

REF REF

Second

1.38 ( 0.79 to 2.40$)$

Third

1.31 (0.73 to 2.38$)$

1.46 (0.80 to 2.67)

Fourth

1.26 (0.69 to 2.31)

1.23 (0.67 to 2.27$)$

Fifth-most

1.18 (0.65 to 2.14$)$

0.95 (0.50 to 1.81

1.03 (0.56 to 1.91$)$

Domestic status

Married/coresiding

REF REF

Single/widowed/divorced

0.97 (0.61 to 1.55$)$

0.79 (0.47 to 1.33$)$

Tumour

\begin{tabular}{|c|c|c|}
\hline Colon & REF & REF \\
\hline Rectum & 1.42 (0.98 to 2.06$)$ & 1.05 (0.60 to 1.84$)$ \\
\hline \multicolumn{3}{|l|}{ Radiotherapy } \\
\hline No & REF & REF \\
\hline Yes & $1.61 \ddagger(1.05$ to 2.46$)$ & 1.47 (0.82 to 2.63$)$ \\
\hline \multicolumn{3}{|l|}{ Chemotherapy } \\
\hline No & REF & REF \\
\hline Yes & 1.07 (0.74 to 1.55$)$ & $0.83(0.55$ to 1.24$)$ \\
\hline \multicolumn{3}{|l|}{ Stoma (at 3 months) } \\
\hline No & REF & REF \\
\hline Yes & $1.50 \ddagger(1.02$ to 2.20$)$ & 1.24 (0.74 to 2.06$)$ \\
\hline Did not participate at 3 months & $1.85(0.93 ; 3.67)$ & 1.51 (0.70 to 3.29$)$ \\
\hline \multicolumn{3}{|l|}{ Surgery type } \\
\hline Laparoscopic & REF & REF \\
\hline Open surgery & $0.98(0.67$ to 1.44$)$ & 0.84 (0.55 to 1.27$)$ \\
\hline Unknown & 1.94 (0.91 to 4.12$)$ & $1.33(0.53$ to 3.31$)$ \\
\hline \multicolumn{3}{|c|}{ Self-efficacy (Self-efficacy for managing chronic disease instrument) } \\
\hline Low confidence & REF & REF \\
\hline Moderate confidence & $0.53(0.27$ to 1.04$)$ & $0.64(0.31$ to 1.35$)$ \\
\hline Confident & $0.33 \S(0.18 ; 0.61)$ & $0.48 \ddagger(0.24$ to 1.00$)$ \\
\hline Very confident & $0.25 \S(0.13 ; 0.49)$ & $0.42 \ddagger(0.19$ to 0.94$)$ \\
\hline \multicolumn{3}{|l|}{ Anxiety STAI (STAI score $>40)$ ) } \\
\hline No & REF & REF \\
\hline Yes & 1.779 (1.20 to 2.60$)$ & $1.08(0.64$ to 1.81$)$ \\
\hline \multicolumn{3}{|c|}{ Depression Centre for Epidemiological Studies Depression scale score >20) } \\
\hline No & REF & REF \\
\hline Yes & $2.69 \S(1.68$ to 4.32$)$ & $2.01 \ddagger(1.12$ to 3.61$)$ \\
\hline
\end{tabular}

Continued 


\section{Step $1^{*}$ \\ OR $(95 \% \mathrm{Cl})$ \\ Step $2 \dagger$ \\ OR $(95 \% \mathrm{Cl})$}

Social support Medical Outcomes Study Social Support Survey)

\begin{tabular}{lll}
$<100$ score & REF & REF \\
Score $=100$ (full support) & $0.529(0.33$ to 0.81$)$ & $0.56 \ddagger(0.35$ to 0.91$)$ \\
\hline
\end{tabular}

${ }^{*}$ Adjusting for time and considering each covariate separately.

†Fully adjusted model, including time and all covariates.

$\ddagger \mathrm{p}<.05$.

$\S \mathrm{p}<.001$.

Ip $<.01$.

STAI, State Trait Anxiety Inventory.

months). Given the low prevalence of poor sexual well-being in women, logistic regression models were only produced for men.

\section{Presurgery predictors of poor sexual well-being among men at 24 months postsurgery}

Data were analysed for 433 men who provided at least one report of sexual well-being over 3-24 months. Of these, 37 did not participate at baseline, and therefore, were excluded from the analyses. The total analytical sample consisted of 1304 observations from 396 men. Results are presented in table 2. (Prevalence of poor sexual wellbeing by each of the covariates is shown in online supplemental table 3).

In the first step, modelling the prevalence of poor sexual well-being from baseline up to 24 months (adjusting for time and considering each covariate separately), having radiotherapy or a stoma increased the odds of poor sexual well-being up to 24 months postsurgery by $50 \%-60 \% \quad(\mathrm{OR}=1.61$ and $\mathrm{OR}=1.50$, respectively, $\mathrm{p}<0.05)$. In addition, all four of the psychosocial measures at baseline were significantly associated with poor sexual well-being $(\mathrm{p}<0.01)$. The analyses show that the odds of reporting poor sexual well-being over the first 24 months postsurgery were: $67 \%-75 \%$ lower among confident/very confident men $(\mathrm{OR}=0.33$ and $\mathrm{OR}=0.25$, respectively); $48 \%$ lower for men who received full social support $(\mathrm{OR}=0.52) ; 77 \%$ higher for men with high anxiety $(\mathrm{OR}=1.77)$; and almost three times higher for men with clinically significant levels of depression $(\mathrm{OR}=2.69)$ at baseline. In the second step of modelling (including time and all covariates), neither of the clinical variables remained significantly associated with sexual well-being. However, all the psychosocial variables except anxiety remained significant. The odds of reporting poor sexual well-being were: $52 \%-58 \%$ lower for confident/ very confident men $(\mathrm{OR}=0.48$ and 0.42$)$; twice as high for men with clinical levels of depression $(\mathrm{OR}+2.01)$; and $44 \%$ lower for men with full social support at baseline $(\mathrm{OR}=0.56)$.
Twenty-four-month postsurgery predictors of poor sexual well-being up to 60 months postsurgery

There were 281 men with at least one reported outcome of sexual well-being over 36-60 months, of whom 21 did not participate at 24 months and therefore were excluded from the analyses. The total analytical sample consisted of 640 observations from 260 men. Model results are presented in table 3. (Prevalence of poor sexual wellbeing by each of the predictors is shown in online supplemental table 4).

In the first step of modelling (adjusting for time and considering each predictor separately), having a stoma at 24 months predicted poor sexual well-being at later time points $(\mathrm{OR}=2.30)$. In addition, all the psychosocial and quality of life factors at 24 months were significantly associated with sexual well-being up to 60 months. The odds of having poor sexual well-being over the last 3 years of follow-up were: 3-5 times higher among men with high anxiety $(\mathrm{OR}=3.41)$ and clinical levels of depression $(\mathrm{OR}=5.61)$; and were significantly lower among men who were very confident $(\mathrm{OR}=0.14)$ and men who had full social support $(\mathrm{OR}=0.26)$. Men with a higher quality of life/Global Health score at 24 months were less likely to report poor sexual well-being in later years $(\mathrm{OR}=0.97)$. The odds of poor sexual well-being at $3-5$ years postsurgery significantly increased if men reported clinically significant problems with body image $(\mathrm{OR}=3.90)$, fatigue $(\mathrm{OR}=3.04)$ or pain $(\mathrm{OR}=1.73)$ at 24 months.

In the second step of the modelling (including time and all predictors in one model), having a stoma at 24 months remained a strong predictor of poor sexual well-being at later time points $(\mathrm{OR}=2.67)$. However, none of the psychosocial or quality of life factors remained significant, suggesting that their relationship with poor sexual well-being was explained by the presence of a stoma at 24 months.

\section{DISCUSSION}

Sexual morbidity is a known consequence of treatment for colorectal cancer, ${ }^{55}$ although it has been identified 
Table 3 Logistic regression modelling (ORs and 95\% Cls) of poor sexual well-being among men after 24 months by the covariates reported at 24 months $(\mathrm{N}=260)$

$\begin{array}{ll}\text { Step } 1^{*} & \text { Step } 2 \dagger \\ \text { ORs }(95 \% \mathrm{Cl}) & \text { ORs }(95 \% \mathrm{Cl})\end{array}$

\section{Age group}

$\begin{array}{lll}\leq 59 & \text { REF } & \text { REF } \\ 60-69 & 1.52(0.64 \text { to } 3.61) & 3.11 \text { (0.97 to 9.95) } \\ 70+ & 1.29(0.54 \text { to } 3.08) & 2.01 \text { (0.59 to } 6.86)\end{array}$

Deprivation index quintiles

$\begin{array}{lll}\text { First-least } & \text { REF } & \text { REF } \\ \text { Second } & 1.25(0.61 \text { to } 2.58) & 1.30 \text { (0.54 to } 3.16) \\ \text { Third } & 1.43(0.67 \text { to } 3.02) & 1.09 \text { (0.44 to } 2.68) \\ \text { Fourth } & 1.71(0.81 \text { to } 3.63) & 1.08 \text { (0.43 to } 2.71) \\ \text { Fifth-most } & 1.87(0.89 \text { to } 3.92) & 1.57 \text { (0.60 to } 4.11)\end{array}$

Domestic status

Married/coresiding

Single/widowed/divorced

Tumour

\begin{tabular}{|c|c|c|}
\hline Colon & REF & REF \\
\hline Rectum & $1.32(0.82$ to 2.14$)$ & $1.30(0.57$ to 2.96$)$ \\
\hline \multicolumn{3}{|l|}{ Radiotherapy } \\
\hline No & REF & REF \\
\hline Yes & 1.40 (0.79 to 2.51$)$ & 0.47 (0.18 to 1.22$)$ \\
\hline \multicolumn{3}{|l|}{ Chemotherapy } \\
\hline No & REF & REF \\
\hline Yes & $0.84(0.52$ to 1.37$)$ & $0.56(0.30$ to 1.07$)$ \\
\hline \multicolumn{3}{|l|}{ Stoma } \\
\hline No & REF & REF \\
\hline Yes & $2.30 \ddagger(1.22$ to 4.34$)$ & $2.67 \ddagger(1.11$ to 6.40$)$ \\
\hline \multicolumn{3}{|l|}{ Surgery type } \\
\hline Laparoscopic & REF & REF \\
\hline Open surgery & 0.80 (0.48 to 1.33$)$ & $0.54(0.28$ to 1.04$)$ \\
\hline Unknown & $3.40 \ddagger(1.18$ to 9.74$)$ & $1.74(0.52$ to 5.74$)$ \\
\hline \multicolumn{3}{|c|}{ Self-efficacy Cancer Survivor Self-efficacy Scale) } \\
\hline Low confidence & REF & REF \\
\hline Moderate confidence & $1.01(0.307$ to 3.335$)$ & $1.30(0.29$ to 5.84$)$ \\
\hline Confident & $0.70(0.232$ to 2.096$)$ & $1.58(0.31$ to 8.05$)$ \\
\hline Very confident & $0.14 \S(0.047$ to 0.44$)$ & $0.33(0.05$ to 1.97$)$ \\
\hline \multicolumn{3}{|c|}{ Anxiety State Trait Anxiety Inventory score $>40$ ) } \\
\hline No & REF & REF \\
\hline Yes & 3.41 (1 $(1.62$ to 7.18$)$ & $1.13(0.31$ to 4.11$)$ \\
\hline \multicolumn{3}{|c|}{ Depression Centre for Epidemiological Studies Depression scale score $>20$ ) } \\
\hline No & REF & REF \\
\hline Yes & $5.61 \S(2.58$ to 12.21$)$ & $2.58(0.81$ to 8.25$)$ \\
\hline \multicolumn{3}{|c|}{ Social support (Medical Outcomes Study Social Support Survey) } \\
\hline$<100$ score & REF & REF \\
\hline Score $=100$ (full support) & $0.26 \S(0.13$ to 0.53$)$ & $0.59(0.26$ to 1.32$)$ \\
\hline
\end{tabular}

REF

REF

1.18 (0.66 to 2.11 )

0.57 (0.28 to 1.15$)$

REF

REF

REF

REF

Yes

REF

REF

0.56 (0.30 to 1.07 )

REF

Yes

$2.30 \ddagger$ (1.22 to 4.34 )

$2.67 \ddagger(1.11$ to 6.40$)$

Surgery type

Laparoscopic

0.80 (0.48 to 1.33$)$

0.54 (0.28 to 1.04 )

Unknown

$3.40 \ddagger$ (1.18 to 9.74 )

Continued 
Table 3 Continued

$\begin{array}{ll}\text { Step } 1^{*} & \text { Step } 2 \dagger \\ \text { ORs }(95 \% \mathrm{Cl}) & \text { ORs }(95 \% \mathrm{Cl})\end{array}$

\begin{tabular}{|c|c|c|}
\hline No & REF & REF \\
\hline Yes, clinically significant & $3.90 \S(1.92$ to 7.93$)$ & 1.71 (0.66 to 4.43$)$ \\
\hline \multicolumn{3}{|l|}{ Fatigue (EORTC QLQ-C30) } \\
\hline No & REF & REF \\
\hline Yes, clinically significant & $3.04 \S(1.74$ to 5.32$)$ & $1.67(0.77$ to 3.64$)$ \\
\hline \multicolumn{3}{|l|}{ Pain (EORTC QLQ-C30) } \\
\hline No & REF & REF \\
\hline Yes, clinically significant & $1.73 \neq(1.04$ to 2.88$)$ & $0.61(0.29$ to 1.26$)$ \\
\hline \multicolumn{3}{|c|}{ Quality of life/Global Health (EORTC QLQ-C30) } \\
\hline Mean (SD) & $0.97 \S(0.95$ to 0.98$)$ & 0.99 (0.97 to 1.02$)$ \\
\hline
\end{tabular}

*Adjusting for time and considering each covariate separately.

†Fully adjusted model, including time and all covariates.

$\neq \mathrm{p}<.05$.

$\S \mathrm{p}<.001$

Ip $<.01$.

that support for sexual problems is seldom offered or sought. ${ }^{56}$ Health professionals may lack knowledge, skills and confidence to address these issues ${ }^{57}$; patients may lack confidence, have low expectations of help or feel unentitled to help. ${ }^{58}$ Knowing which people treated for colorectal cancer are likely to experience problems with sexual well-being, and over what time frame, is important for the delivery of personalised care and for the development of interventions to address such problems. CREW is the largest longitudinal study to date to explore a broad range of aspects of recovery from colorectal cancer, including sexual well-being. It has followed a representative UK sample from presurgery to 5 years postsurgery between 2010 and 2012. It is also one of a few studies to consider psychosocial predictors of sexual well-being.

More than one-third of the men in the study reported poor sexual well-being 5 years after their treatment for colorectal cancer. We identified a range of psychosocial variables-depression, anxiety, social support and selfefficacy-that were predictive of poor sexual well-being among men over the 5-year period. This is in support of Foster and Fenlon's framework of recovery of health and well-being, ${ }^{19}$ which suggests the importance of wider personal and environmental factors in influencing wellbeing and coping. Use of such markers to identify people at risk would allow early intervention. Of particular note is that men who had higher levels of self-efficacy were less likely to report poor sexual well-being. This finding suggests that targeting improvements in self-efficacy may be a helpful focus for intervention to enhance sexual well-being. This is supported by reviews of interventions for sexual difficulties following cancer, ${ }^{59} 60$ which highlight the importance of a self-efficacy element. However, further investigation of this association and of appropriate interventions to boost self-efficacy is warranted. As selfefficacy is domain specific, with cancer survivors potentially having different levels of self-efficacy according to $\operatorname{task}^{61}$, the use of measures specific to sexual well-being, such as the Sexual Self-Efficacy Scale for Female Functioning $^{62}$ or the SECSI scale ${ }^{33}$ should be considered.

Men with a stoma were also at increased risk of poor sexual well-being. Stoma-related sexual problems and negative associations of stoma with overall quality of life have been shown cross-sectionally. ${ }^{63}$ Our findings indicate that it is important to discuss sexual well-being with men who require a stoma soon after their surgery and to continue those conversations over the longer term.

There was also a significant increase in poor sexual well-being among men over time. It has previously been suggested that there may be a focus on survival in the early phase of the cancer trajectory, with other issues becoming more important over time. ${ }^{5865}$ This illustrates the importance of continued screening and attention to sexual wellbeing among men over the whole course of surveillance.

Fewer women reported poor sexual well-being, with a stable pattern of around 10\%-15\% over time. Questions about sexual well-being were asked of all participants regardless of their sexual activity level, partnership status or level of interest in sex at baseline. The fact that fewer women than men reported being married/coresiding and fewer reported an interest in sex might explain why fewer women reported poor sexual well-being. Conversely, women may undertake a renegotiation of sexual activity, through non-coital sexual practices and a focus on intimacy. ${ }^{66}$ Nonetheless, poor sexual well-being is clearly an issue for some women post cancer treatment and further research to provide greater understanding of this group remains important. 


\section{Limitations}

While there are numerous strengths to the study, such as the prospective, longitudinal design with presurgery assessment point and long-term follow-up, and the large and representative sample, there are some limitations which need to be considered. First, while study response rates were high, there were lower response rates to sexual well-being questions. For instance, at presurgery baseline $3 \%$ of men and $13 \%$ of women did not provide a sexual well-being score. Women were more likely overall to return a non-response to these questions. Second, it was not possible to run predictive models for women, due to the small number reporting poor sexual well-being. Less is known about women's sexual problems after colorectal cancer, partly because of commonly lower response rates to questions about sexuality from women. ${ }^{24}$ We did not ask about sexual activity and cannot assess whether nonresponse was due to perceived irrelevance of the questions among those who were sexually inactive. Finally, while sexual well-being is a multifaceted construct, ${ }^{66}$ it was operationalised using a two item scale of bother and satisfaction. Research in this field would benefit from standardised definitions and measures.

\section{Clinical implications}

Screening, support and appropriate referral for the sexual consequences of cancer and its treatment is an essential part of personalised care. Clinicians should consider sexual well-being as well as sexual function, in order to take account of meanings that patients attribute to sexual changes following cancer treatment ${ }^{13}$ and to best understand where intervention might be welcomed. Psychosocial indicators could be useful for identifying people at risk of poor sexual well-being, allowing early intervention to enhance sexual adaptation. A focus on improving self-efficacy levels could help to improve sexual well-being. The long-term nature of sexual well-being issues reinforces the need for ongoing survivorship support.

\section{CONCLUSION}

While previous research has provided understanding of the prevalence and predictors of sexual dysfunction postcolorectal cancer treatment, much less is understood about sexual well-being. This is one of a few studies to consider a broad range of treatment and psychosocial factors associated with sexual well-being for people treated for colorectal cancer. Assessment of psychosocial factors could help identify those at risk of poor sexual well-being, allowing for early and continued intervention. In light of findings that patients rarely seek help for sexual problems, such predictors are of vital importance to a proactive approach from health professionals.

\section{Author affiliations}

${ }^{1}$ Macmillan Survivorship Research Group, School of Health Sciences, University of Southampton, Southampton, UK
${ }^{2}$ University Hospital Southampton NHS Foundation Trust, Southampton, UK ${ }^{3}$ College of Human and Health Sciences, Swansea University, Swansea, UK ${ }^{4}$ School of Health Sciences, University of Southampton, Southampton, UK ${ }^{5}$ Social Statistics and Demography, University of Southampton, Southampton, UK

Acknowledgements We thank all CREW study participants; recruiting NHS Trusts; members of the Macmillan Survivorship Research Group; Research Partners; and members of the Study Advisory Committee.

Contributors $\mathrm{CF}$ is the overall project lead and grant holder with responsibility for the design and execution of the protocol. CF, AR, PWS, DF, JW, PWS and LC contributed to the design of the CREW study. LC and DF managed data collection. JW provided clinical expertise. JF, SW and NVP designed the data analysis plan. SW and NVP undertook data analysis. JF, NC, DW and SW drafted the paper. All authors read, commented on and approved the final manuscript.

Funding The ColoREctal Well-being study (CREW) was funded by Macmillan Cancer Support grant number 3546834.

Competing interests Deborah Fenlon has received an honorarium from Roche.

Patient consent for publication Not required.

Ethics approval The study was granted ethical approval by the UK National Health Service National Research Ethics Service (REC reference number: 10/H0605/31).

Provenance and peer review Not commissioned; externally peer reviewed.

Data availability statement Data are available on reasonable request. Access to deidentified data can be requested at http://www.horizons-hub.org.uk/access_ data.html

Supplemental material This content has been supplied by the author(s). It has not been vetted by BMJ Publishing Group Limited (BMJ) and may not have been peer-reviewed. Any opinions or recommendations discussed are solely those of the author(s) and are not endorsed by BMJ. BMJ disclaims all liability and responsibility arising from any reliance placed on the content. Where the content includes any translated material, BMJ does not warrant the accuracy and reliability of the translations (including but not limited to local regulations, clinical guidelines, terminology, drug names and drug dosages), and is not responsible for any error and/or omissions arising from translation and adaptation or otherwise.

Open access This is an open access article distributed in accordance with the Creative Commons Attribution Non Commercial (CC BY-NC 4.0) license, which permits others to distribute, remix, adapt, build upon this work non-commercially, and license their derivative works on different terms, provided the original work is properly cited, appropriate credit is given, any changes made indicated, and the use is non-commercial. See: http://creativecommons.org/licenses/by-nc/4.0/.

ORCID iD

Claire Foster http://orcid.org/0000-0002-4703-8378

\section{REFERENCES}

1 Albaugh JA, Tenfelde S, Hayden DM. Sexual dysfunction and intimacy for Ostomates. Clin Colon Rectal Surg 2017;30:201-6.

2 Averyt JC, Nishimoto PW. Addressing sexual dysfunction in colorectal cancer survivorship care. J Gastrointest Oncol 2014;5:388-94.

3 Canty J, Stabile C, Milli L, et al. Sexual function in women with Colorectal/Anal cancer. Sex Med Rev 2019;7:202-22.

4 Donovan KA, Thompson LMA, Hoffe SE. Sexual function in colorectal cancer survivors. Cancer Control 2010;17:44-51.

5 Ho VP, Lee Y, Stein SL, et al. Sexual function after treatment for rectal cancer: a review. Dis Colon Rectum 2011;54:113-25.

6 Breukink SO, Donovan KA. Physical and psychological effects of treatment on sexual functioning in colorectal cancer survivors. J Sex Med 2013;10 Suppl 1:74-83.

7 Panjari M, Bell RJ, Burney S, et al. Sexual function, incontinence, and wellbeing in women after rectal cancer--a review of the evidence. $J$ Sex Med 2012;9:2749-58.

8 Thyø A, Elfeki H, Laurberg S, et al. Female sexual problems after treatment for colorectal cancer - a population-based study. Colorectal Dis 2019;21:1130-9.

9 Bober SL, Varela VS. Sexuality in adult cancer survivors: challenges and intervention. J Clin Oncol 2012;30:3712-9.

10 Hordern AJ, Street AF. Constructions of sexuality and intimacy after cancer: patient and health professional perspectives. Soc Sci Med 2007;64:1704-18. 
11 Syme ML, Mona LR, Cameron RP, et al. Sexual Health and Well-Being After Cancer:Applying the Sexual Health Model. The Counseling Psychologist 2013;41:268-85.

12 Hordern A. Intimacy and sexuality after cancer: a critical review of the literature. Cancer Nurs 2008;31:E9-17.

13 Ussher JM, Perz J, Gilbert E. Changes to sexual well-being and intimacy after breast cancer. Cancer Nurs 2012;35:456-65.

14 Ussher JM, Perz J, Gilbert E, et al. Perceived causes and consequences of sexual changes after cancer for women and men: a mixed method study. BMC Cancer 2015;15:268.

15 Lorimer K, DeAmicis L, Dalrymple J, et al. A rapid review of sexual wellbeing definitions and measures: should we now include sexual wellbeing freedom? J Sex Res 2019;56:843-53.

16 World Health Organisation. Measuring sexual health: Conceptual and practical considerations and related indicators. Geneva: WHO, 2010.

17 CHANGE Centre for Health and Gender Equity. Sexual wellbeing. Washington DC: CHANGE, 2018.

18 Flynn KE, Jeffery DD, Keefe FJ, et al. Sexual functioning along the cancer continuum: focus group results from the patientreported outcomes measurement information system (PROMIS $®$ ). Psychooncology 2011;20:378-86.

19 Foster C, Fenlon D. Recovery and self-management support following primary cancer treatment. Br J Cancer 2011;105 Suppl 1:S21-8.

20 Globocan. Global cancer incidence, 2018. Available: https://www. uicc.org/news/new-global-cancer-data-globocan-2018 [Accessed 15 Nov 2019].

21 Hendren SK, O'Connor BI, Liu M, et al. Prevalence of male and female sexual dysfunction is high following surgery for rectal cancer. Ann Surg 2005;242:212-23.

22 Den Oudsten BL, Traa MJ, Thong MSY, et al. Higher prevalence of sexual dysfunction in colon and rectal cancer survivors compared with the normative population: a population-based study. Eur $J$ Cancer 2012;48:3161-70.

23 Mahjoubi B, Mirzaei R, Azizi R, et al. A cross-sectional survey of quality of life in colostomates: a report from Iran. Health Qual Life Outcomes 2012;10:136.

24 Milbury K, Cohen L, Jenkins R, et al. The association between psychosocial and medical factors with long-term sexual dysfunction after treatment for colorectal cancer. Support Care Cancer 2013;21:793-802.

25 Traa MJ, Roukema JA, De Vries J, et al. Biopsychosocial predictors of sexual function and quality of sexual life: a study among patients with colorectal cancer. Transl Androl Urol 2015;4:206-17.

26 Ang SGM, Chen H-C, Siah RJC, et al. Stressors relating to patient psychological health following stoma surgery: an integrated literature review. Oncol Nurs Forum 2013;40:587-94.

27 Downing A, Morris EJA, Richards M, et al. Health-Related quality of life after colorectal cancer in England: a patient-reported outcomes study of individuals 12 to 36 months after diagnosis. J Clin Oncol 2015;33:616-24.

28 Tripaldi C. Sexual function after stoma formation in women with colorectal cancer. Br J Nurs 2019;28:S4-15.

29 Traa MJ, De Vries J, Roukema JA, et al. Sexual (dys)function and the quality of sexual life in patients with colorectal cancer: a systematic review. Ann Oncol 2012;23:19-27.

30 Reese JB, Handorf E, Haythornthwaite JA. Sexual quality of life, body image distress, and psychosocial outcomes in colorectal cancer: a longitudinal study. Support Care Cancer 2018;26:3431-40.

31 Dorfman CS, Arthur SS, Kimmick GG, et al. Partner status moderates the relationships between sexual problems and self-efficacy for managing sexual problems and psychosocial quality-of-life for postmenopausal breast cancer survivors taking adjuvant endocrine therapy. Menopause 2019;26:823-32.

32 Campbell LC, Keefe FJ, McKee DC, et al. Prostate cancer in African Americans: relationship of patient and partner self-efficacy to quality of life. J Pain Symptom Manage 2004;28:433-44.

33 Arthur EK, Wills CE, Browning K, et al. The self-efficacy to communicate about sex and intimacy (SECSI) scale: psychometric assessment in women treated for cancer. Support Care Cancer 2020;28:1449-57.

34 Laumann EO, Paik A, Glasser DB, et al. A cross-national study of subjective sexual well-being among older women and men: findings from the global study of sexual attitudes and behaviors. Arch Sex Behav 2006:35:143-59.

35 Perz J, Ussher JM, Gilbert E, et al. Feeling well and talking about sex: psycho-social predictors of sexual functioning after cancer. BMC Cancer 2014:14:228

36 Fenlon D, Richardson A, Addington-Hall J, et al. A cohort study of the recovery of health and wellbeing following colorectal cancer (crew study): protocol paper. BMC Health Serv Res 2012;12:90.
37 National Institute for Health and Care Excellence. Colorectal cancer: diagnosis and management, 2019.

38 National Institute for Health and Care Excellence. Colorectal cancer: diagnosis and management, 2011. Available: https://www.nice.org. uk/guidance/cg131 [Accessed 17 Dec 2019].

39 Sodergren SC, Wheelwright SJ, Permyakova NV, et al. Supportive care needs of patients following treatment for colorectal cancer: risk factors for unmet needs and the association between unmet needs and health-related quality of life-results from the colorectal wellbeing (crew) study. J Cancer Surviv 2019;13:899-909.

$40 \mathrm{NHS}$. Improvement, Innovation to implementation: Stratified pathways of care for people living with or beyond cancer. A thow to guide'. London, 2013.

41 Corner J, Wright D, Hopkinson J, et al. The research priorities of patients attending UK cancer treatment centres: findings from a modified nominal group study. Br J Cancer 2007;96:875-81.

42 Avis NE, Ip E, Foley KL. Evaluation of the quality of life in adult cancer survivors (QLACS) scale for long-term cancer survivors in a sample of breast cancer survivors. Health Qual Life Outcomes 2006:4:92.

43 GOV.UK. English indices of deprivation, 2015.

44 Lorig KR, Ritter P, Stewart AL, et al. Chronic disease selfmanagement program: 2-year health status and health care utilization outcomes. Med Care 2001;39:1217-23.

45 Grimmett C, Haviland J, Winter J, et al. Colorectal cancer patient's self-efficacy for managing illness-related problems in the first 2 years after diagnosis, results from the ColoREctal Well-being (CREW) study. J Cancer Surviv 2017:11:634-42.

46 Radloff LS. The CES-D scale: a self-report depression scale for research in the general population. Applied psychological measurement 1977:1:385-401.

47 Katz MR, Kopek N, Waldron J, et al. Screening for depression in head and neck cancer. Psychooncology 2004;13:269-80.

48 Spielberger CD. State-trait anxiety inventory for adults, 1983.

49 Knight RG, Waal-Manning HJ, Spears GF. Some norms and reliability data for the State--Trait Anxiety Inventory and the Zung Self-Rating Depression scale. Br J Clin Psychol 1983;22 (Pt 4:245-9.

50 Sherbourne CD, Stewart AL. The mos social support survey. Soc Sci Med 1991;32:705-14.

51 Aaronson NK, Ahmedzai S, Bergman B, et al. The European organization for research and treatment of cancer QLQ-C30: a quality-of-life instrument for use in international clinical trials in oncology. J Natl Cancer Inst 1993;85:365-76.

52 Whistance RN, Conroy T, Chie W, et al. Clinical and psychometric validation of the EORTC QLQ-CR29 questionnaire module to assess health-related quality of life in patients with colorectal cancer. Eur $J$ Cancer 2009;45:3017-26.

53 Giesinger JM, Loth FLC, Aaronson NK, et al. Thresholds for clinical importance were established to improve interpretation of the EORTC QLQ-C30 in clinical practice and research. J Clin Epidemiol 2020:118:1-8.

54 Wheelwright S, Permyakova NV, Calman L, et al. Does quality of life return to pre-treatment levels five years after curative intent surgery for colorectal cancer? Evidence from the colorectal wellbeing (crew) study. PLoS One 2020;15:e0231332.

55 Towe M, Huynh LM, El-Khatib F, et al. A review of male and female sexual function following colorectal surgery. Sex Med Rev 2019;7:422-9.

56 Reese JB, Sorice K, Beach MC, et al. Patient-Provider communication about sexual concerns in cancer: a systematic review. J Cancer Surviv 2017:11:175-88.

57 Stead ML, Brown JM, Fallowfield L, et al. Lack of communication between healthcare professionals and women with ovarian cancer about sexual issues. Br J Cancer 2003;88:666-71.

58 Dowswell G, Ismail T, Greenfield S, et al. Men's experience of erectile dysfunction after treatment for colorectal cancer: qualitative interview study. BMJ 2011;343:d5824.

59 Brotto LA, Yule M, Breckon E. Psychological interventions for the sexual sequelae of cancer: a review of the literature. J Cancer Surviv 2010;4:346-60.

60 Arthur EK, Wills CE, Menon U. A systematic review of interventions for sexual well-being in women with gynecologic, anal, or rectal cancer. Oncol Nurs Forum 2018;45:469-82.

61 Foster C, Breckons M, Cotterell P, et al. Cancer survivors' selfefficacy to self-manage in the year following primary treatment. $J$ Cancer Surviv 2015;9:11-19.

62 Bailes S CL, Fichten CS, Libman E, et al. Sexual Self-Efficacy Scale for Female Functioning. In: Fisher TD, Yarber WL, Davis SL, et al, eds. Handbook of sexuality-related measures., D.C. New York: Routledge, 2010 
63 Sprunk E, Alteneder RR. The impact of an ostomy on sexuality. Clin J Oncol Nurs 2000;4:85-8.

64 Vonk-Klaassen SM, de Vocht HM, den Ouden MEM, et al. Ostomy-related problems and their impact on quality of life of colorectal cancer ostomates: a systematic review. Qual Life Res 2016;25:125-33.
65 Ball M, Nelson CJ, Shuk E, et al. Men's experience with sexual dysfunction post-rectal cancer treatment: a qualitative study. $J$ Cancer Educ 2013;28:494-502.

66 Ussher JM, Perz J, Gilbert E. Women's Sexuality after Cancer: A Qualitative Analysis of Sexual Changes and Renegotiation. Women Ther 2014;37:205-21. 